\title{
Consonant Changes in Words Borrowed From Sanskrit to Thai and Patani Malay
}

\author{
Angsana Na Songkhla (Corresponding author) \\ School of Languages, Literacies and Translation \\ Universiti Sains Malaysia, Penang, Malaysia \\ Tel: 60-17-498-0992Ｅ-mail: angsanahu@ gmail.com
}

Ilangko Subramaniam

School of Languages, Literacies and Translation

Universiti Sains Malaysia, Penang, Malaysia

Tel: 60-12-565-8754 E-mail: ilangko@usm.my

Received: August 23, 2021 Accepted: September 29, $2021 \quad$ Published: October 8, 2021

doi:10.5296/ijl.v13i5.18957 URL: https://doi.org/10.5296/ijl.v13i5.18957

\begin{abstract}
Southeast Asia was under Indian influence for more than a thousand years so that the traces of Indian civilization can be determined from a lot of evidence. The entry of Indian civilization in this region has shown that Sanskrit has merged with Thai, the national language of Thailand, and Patani Malay, the mother tongue language of Thai Malays who live in the deep south of Thailand. Borrowing is a process of language contact and language change that can happen in all languages and is not limited to borrow in the same language family or the same type of language. All of them belong to different family trees. Sanskrit is a member of the Indo-European language family, whereas the Thai language is accepted to Tai-Kadai and Patani Malay belongs to the Austronesian language family. This study aims to study consonant changes of shared Sanskrit loanwords in Thai and Patani Malay. This research employed qualitative methodology. Data were collected from documentaries. The findings showed that changes in consonant phonemes occurred in both languages according to phonological adaptations such as deletion, insertion, voicing, devoicing, and substitution.
\end{abstract}

Keywords: Lexical borrowing, Sanskrit loanwords, Consonant changes, Thai, Patani Malay 


\section{Introduction}

Thailand is in the center of Southeast Asia, so there is a great diversity of languages and cultures seen in the country. In the deep south of Thailand, the majority of the population is ethnic Thai Malays. Salae (1991) stated that the Malay language spoken in the deep south is one of the branches of Malay dialects called Patani Malay. It is widely spoken in the provinces of Pattani, Yala, Narathiwat, and some districts in Songkhla (Uthai, 2013). Therefore, Patani Malay can be regarded as the mother tongue of Thai Malays and the Thai language as a secondary language for communication in their daily lives.

Thai and Patani Malay are in different language families. Li (1965), cited in Burusphat (2000), classified the Tai language family into 3 groups and the Thai language belongs to the Southwest branch. Moreover, Thai is perceived as isolating language that is each word in the language is free to enter into the construction of sentences, without any modification as to the case, gender, number, mood, or tense (Sarapadnuke, 2001). In contrast, Patani Malay is a dialect of the Malay language that belongs to the Austronesian language family. Umaiyah (2010) explained that the Malay language is an agglutinative language. Words are created by adding morphemes known as affixes (suffixes, infixes, and prefixes) to the root words which often have two syllables to express grammatical functions and define the meaning in the sentence. Although these two languages are different. But both languages have long been influenced by Sanskrit for the long term.

\subsection{Background of Sanskrit in Thai and Patani Malay}

The longest language contact phenomenon in Southeast Asia is the entry of the Sanskrit language. Sanskrit is one of the oldest languages of the world that influenced other languages in the manner of borrowing words. The arrival of Sanskrit is the outcome of language contact from Indian civilization. Coedes (1975) named the influence of Indian civilization in Southeast Asia as "Indianization" or "Sanskritization". As a result of this incident since the $1^{\text {st }}$ century, the Sanskrit language had infiltrated into the language of the indigenous people in this region. Sanskrit has been used to expand the local people's vocabularies according to the needs of the indigenous society of those days. In the present day, Sanskrit is still used in this area as a loanword and has exercised a great impact on the Southeast Asian nations (Ramana, 2001). Even though the cultural infiltration of Indianization ceased in the $13^{\text {th }}$ century, its cultural heritage remains deeply embedded in the people of this area. Particularly, Thailand as present-day, which was once the site of various ancient kingdoms such as Dvaravati, Srivijaya, and Langkasuka. It found inscriptions recorded by the Sanskrit language spread over this country.

Based on this evidence, it clearly shows the period of the arrival and confirms the existence of the Sanskrit language in Thailand including the deep south of Thailand. We can investigate the traces of the language that resulted from language contact. Especially Sanskrit words that appeared and are still used in the Thai and Patani Malay languages.

\subsection{Significance of This Study}

Today, Sanskrit loanwords in Thai and Patani Malay have been adapted with their own 
characteristics in terms of sound, meanings, and uses. Finally, native people are unable to distinguish Sanskrit loanwords from their word mother tongue. Actually, Thai and Thai Malays have shared similar vocabularies in different forms and sounds in terms of the lack of knowledge of root words, historical backgrounds, and the inability to link both languages together. Mehdi and Jaradat (2021) indicated that contrastive analysis means the comparison of the two languages focusing on the differences and similarities between them. Therefore, a comparative study of Sanskrit loanwords in Thai and Patani Malay will be another study that demonstrates how similarity or difference of Sanskrit loanwords in both languages in the present day. The purpose of the present study is to make a comparison of shared Sanskrit loanwords between Thai and Patani Malay. There are different ways of lexical changes while adapting Sanskrit words in both languages such as sound or meaning changes. This research will focus on sound changes, particularly phonological adaptations of consonants. We expected that this research would be significant for both language users.

\section{Literature Review}

\subsection{Language Borrowing}

Due to the scope of this research as it concerns on borrowing, a notable definition of borrowing must be described. Matras (2009) shared a point of view that most societies are multilingual. When different language speakers interact together and most importantly, their language has an influence on each other, so 'language contact' occurs. Language contact, when it happened, will lead to the transfer of language features. Therefore, everyone can learn the vocabulary that neighbors use and derive their words into their own language. This method is called borrowing. For the borrowed word is called loanwords. This process is the outcome of language contact (Millar, 2007). The borrowing of the word comes from the need to increase the number of vocabularies in the language. Lehiste (1988) defined this situation as lexical interference. There are various ways in which the vocabulary of one language may interfere with another language. Using new words to define new concepts will increase the number of words. In addition to that, the entry of vocabulary from other languages will frequently affect the prototype lexicon in that language by replacing the existing words or expand the meaning of the original word to enable the newly borrowed vocabulary to be used. Moreover, Treffers-Daller (2010) referred to language borrowing as the process by which one language derives a meaningful unit from another and loanword is a vocabulary list that was borrowed from another language. The original is not a prototype word in the recipient language, but it is a word of the donor language and the new users made it part of the recipient language.

All points of view above must be more clearly understood in terms of borrowing. Thus, this phenomenon can be explained in the Sanskrit diffusion that originated in the case of Thai and Patani Malay in this research. Because Sanskrit came into the Thai and Patani Malay through the Indian civilization, especially religion and trade, which covered new ideas and inventions that had never been seen before in the indigenous peoples. Therefore, accepting words as borrowed words is the quickest and easiest way to build and increase vocabulary. 


\subsection{Phonological Adaptations}

This study focused on sound changes. Phonological adaptations began to appear widely in linguistic study after this strategy was described by Arlotto (1972) and Campbell (1999), who indicated that sound changes are one of the significant facts for lexical borrowings. Borrowed words assimilate into the phonemic system of the borrowing language. Sounds that do not occur in the borrowing language are either dropped or replaced by familiar, native ones. In addition, Crowley and Bowern (2010) stated that when a language is copied, borrowing words will be remodeled to suit with its own phonological structure. The phonemes never occurred in the borrowed language will be replaced by other phonemes that occur in the system of the borrowed language. For instance, Tongan does not allow consonant clusters at all, nor does it allow word final consonants. Tongan has no distinction between $/ \mathrm{l} /$ and $/ \mathrm{r} /$ either, so when Tongan speakers want to talk about an ice cream, they use a word that has been copied from English into Tongan, with the shape /aisikilimi/. Likewise, Hayes (2010) demonstrated that the German for 'party' is in fact not/pfartsi/ but rather/partai/. This word was borrowed from French, long after the change of sound that converted $*_{t}$ and $* p$ into affricates. Correspondingly, Hussain, Mahmood, \& Mahmood (2011) asserted that during the process of adaptation, a given input sound will be mapped to a closest available phonemic category for donor language. If a sound is absent in the recipient language, it is adapted to the closest available sound.

Sound changes are outstanding sources to verify loanwords. Hence, Chanthao (2011) offered phonological adaptions as criteria to identify Thai loanwords in Lao language in her study. This strategy was emphasized again by Salzmann (2012), who has divided the reasons for sound changes as assimilation, dissimilation, metathesis, and grammatical change by means of which certain irregular forms become regularized. The criterion continues to be used to classify borrowers and to describe the changes that occur in the borrower's language. Naziman and Jaafar (2018) examined the adaptation strategies when English words are borrowed into the Kelantan Malay dialect. She discussed that some phonological patterns occur in the Kelantan Malay dialect whereas they are not formally stated and have never been discussed in the phonological system of the dialect. Due to the sound changes that occur in the Sanskrit loanwords in Thai and Patani Malay, there are different forms because both languages have different language characteristics. Thus, some changes in the Thai language may be found or not found in the Patani Malay and vice versa. Therefore, Phonological adaptations above will be adapted to explain the sound change in this study.

\subsection{Sanskrit, Thai and Patani Malay Phonemic Inventories}

This section presents and compares the inventories of consonant phonemes for Sanskrit, Thai, and Patani Malay. Phoneme inventory is basically important in analyzing loanwords. A brief description of those consonants is necessary when the consonant of the borrower's language is different from the donor's language. Table 1 shows an overview of the vowels of Sanskrit (Perry 1936 and Monier 1999), Thai (Tuaychareon 2004), Patani Malay (Salae 1991 and Royal Institute of Thailand 2010). 
Table 1. Comparison of consonant phonemes between Sanskrit, Thai and Patani Malay

\begin{tabular}{|c|c|c|c|}
\hline & Sanskrit & Thai & Patani Malay \\
\hline Stop & $\begin{array}{l}\mathrm{p}, \mathrm{p}^{\mathrm{h}}, \mathrm{b}, \mathrm{b}^{\mathrm{h}}, \mathrm{t}, \mathrm{t}^{\mathrm{h}}, \mathrm{d}, \\
\mathrm{d}^{\mathrm{h}}, \mathrm{t}, \mathrm{t}^{\mathrm{h}}, \mathrm{d}, \mathrm{d}^{\mathrm{h}}, \mathrm{c}, \mathrm{c}^{\mathrm{h}}, \\
\mathrm{j}, \mathrm{j}^{\mathrm{h}}, \mathrm{k}, \mathrm{k}^{\mathrm{h}}, \mathrm{g}, \mathrm{g}^{\mathrm{h}}\end{array}$ & $\begin{array}{l}\mathrm{p}, \mathrm{p}^{\mathrm{h}}, \mathrm{b}, \mathrm{t}, \mathrm{t}^{\mathrm{h}}, \mathrm{d}, \mathrm{c}, \\
\mathrm{c}^{\mathrm{h}}, \mathrm{k}, \mathrm{k}^{\mathrm{h}}, ?\end{array}$ & $\begin{array}{l}\mathrm{p},\left(\mathrm{p}^{\mathrm{h}}\right), \mathrm{b}, \mathrm{t},\left(\mathrm{t}^{\mathrm{h}}\right), \mathrm{d}, \mathrm{c}, \\
\left(\mathrm{c}^{\mathrm{h}}\right), \mathrm{k},\left(\mathrm{k}^{\mathrm{h}}\right), \dot{j}, \mathrm{~g}, ?\end{array}$ \\
\hline Nasal & $\mathrm{m}, \mathrm{n}, \mathrm{n}, \mathrm{n}, \mathrm{\eta}$ & $\mathrm{m}, \mathrm{n}, \mathrm{y}$ & $\mathrm{m}, \mathrm{n}, \mathrm{n}, \mathrm{n}$ \\
\hline Seminasal & - & - & $\mathrm{m}^{\mathrm{b}}, \mathrm{n}^{\mathrm{d}}, \mathrm{n}^{\mathrm{j}}, \mathrm{y}^{\mathrm{g}}$ \\
\hline Fricative & ś, ș, s, h & $\mathrm{f}, \mathrm{s}, \mathrm{h}$ & $\mathrm{s}, \mathrm{h},(\mathrm{f}),(\mathrm{x}),(\mathrm{z})$ \\
\hline Lateral & $1, \mathrm{r}$ & 1 & 1 \\
\hline Trill & - & $\mathrm{r}$ & $\mathrm{r}$ \\
\hline Semivowels & $\mathrm{v}, \mathrm{j}$ & $w, j$ & $\mathrm{w}, \mathrm{y}$ \\
\hline
\end{tabular}

The above chart shows that Sanskrit has as many as 33 consonant phonemes. Meanwhile, Paramal (1991) and Royal Institute of Thailand (2010) summarized that the consonant phoneme in Patani Malay can be divided into 2 types. First, the phonemes that appear in the Patani Malay word total 24 phonemes as follows; / p, t, c, k, ?, b, d, j, g, s, f, h, l, r, m, n, n, y, $\mathrm{m}^{\mathrm{b}}, \mathrm{n}^{\mathrm{d}}, \mathrm{y}^{\mathrm{g}}, \mathrm{j}^{\mathrm{j}}, \mathrm{w}, \mathrm{y} /$. Second, the phonemes that appear in the borrowed word total 7 phonemes as follows; / $\mathrm{p}^{\mathrm{h}}, \mathrm{t}^{\mathrm{h}}, \mathrm{c}^{\mathrm{h}}, \mathrm{k}^{\mathrm{h}}, \mathrm{f}, \mathrm{z}, \mathrm{x} /$. In the case of borrowed words, it does not include Sanskrit loanwords but it implies borrowed words from other languages such as Thai and Arabic. As for Thai, there are 21 consonant phonemes. From the data, it can be seen that phonemes which do not appear in Thai and Patani Malay are consonants in retroflex articulation /ț $t^{\mathrm{h}}, \mathrm{d}$, $\mathrm{ḍ}^{\mathrm{h}}, \mathrm{n}, \mathrm{s} /$ and fricative palatal /ś/. In addition, Patani Malay has extra 4 phonemes as follows; $/ \mathrm{m}^{\mathrm{b}}, \mathrm{n}^{\mathrm{d}}, \mathrm{n}^{\mathrm{j}}, \mathrm{y}^{\mathrm{g} /}$ which do not appear in Sanskrit and Thai. Those phonemes are produced by combining the nasal consonant phonemes with the consonants which have similar articulation. Moreover, they exist only in the middle of words such as $/ \mathrm{kim}^{\mathrm{b}} \varepsilon /$ 'bloom'.

\subsection{Previous Studies}

Previous studies related to this current study appear in two aspects: Sanskrit loanwords in Thai and Patani Malay. In view of Sanskrit words borrowed into Thai. Pengpala (2006) pointed that Sanskrit has exercised a great impact on the Thai language. The researcher emphasized that "If one deletes Sanskrit words from Thai, a crisis will arise". Additionally, Sarapadnuke (2001) examined that when Sanskrit word is adapted, it may have to undergo plenty of ways such as change of forms and sounds. Further, Buaphanngam (2017) claimed in his study that over half of the loanwords found in Thai are borrowed from Sanskrit. In light of Sanskrit loanwords in Patani Malay, there are a few works regard Sanskrit loanwords in Patani Malay. First of all, from a database of the Inscriptions in Thailand, in the area of the Southern border of Thailand, was once the site of an ancient kingdom which influenced by Indian civilization. The "Ye Dhamma" inscriptions date back 6 A.D. in Yarang Ancient Town, Pattani province was found. Those were recorded in Sanskrit. Unfortunately, there is only one study by Phatyarat (1980) that proposed Sanskrit loanwords in Patani Malay. He found 122 


\section{Mll Macrothink}

International Journal of Linguistics

ISSN 1948-5425

2021, Vol. 13, No. 5

Sanskrit loanwords in Patani Malay. However, he suggested that still have 31 words are assumed as Sanskrit loanwords to be analyzed in further study.

From the outset, we can see that studies have been carried out to study the features of Sanskrit loanwords in Thai and Patani Malay by themselves. There are studies that have been conducted in Sanskrit loanwords in Thai from different perspectives but there is no comparative study with other languages spoken in Thailand such as Patani Malay. More clearly, Chaipunya (2018) asserted in her survey of research works on Sanskrit loanwords in Thailand. The findings showed that there is neither any study on a comparative section of Sanskrit loanwords among both languages nor other languages in Thailand. In addition, studies related to Patani Malay mainly focus on language characteristics. For instance, Bualert (1993) described the structure of compound words in Pattani Malay. Ninlapan (1993) showed that expressive in Pattani Malay are words that occur after verbs or adjectives in order to modify them. And Iemwanthong (2008) analyzed the acoustic characteristics of oral and nasal vowels in open and closed syllables. In particular, the study of loanwords in Patani Malay, which is currently preferable to study only Arabic such as Kaseng (2001) who identified and analyzed types of Arabic loanwords in Patani Malay. This is because Arabic is considered the language that came along with Islam, which is the main religion of the Thai Malays in the present day. Therefore, the study of loanwords of other languages found in Patani Malay other than Arabic is considered to be enriching the knowledge of language users. Especially the study of loanwords like Sanskrit that can be linked Patani Malay to Thai, which is the main language of communication for people in this country. Hence, there is a need to conduct this study to bridge this research gap.

\section{Method}

The goal of this study is to compare the same Sanskrit loanwords between Thai and Patani Malay. In this study, researchers used the descriptive qualitative research method. The same Sanskrit loanwords in Thai and Patani Malay used in this study total 210 words. The data are collected from the latest version of Royal Thai Academy Dictionary that published in 2011 by the Office of Royal Society of Thailand and Patani Malay-Thai dictionaries from Faculty of Humanities and Social Sciences, Prince of Songkla University published in 1984, Institute of Southeast Asian Maritime States Studies, Prince of Songkla University in 2008, and The Resource Center for Revitalization and Maintenance of Language and Cultures, Research Institute for Languages and Cultures of Asia, Mahidol University published in 2015. The data will be written by IPA symbols for Thai and Patani Malay.

\section{Results and Discussion}

This section presents the results of an analysis of the consonant changes. The changes that occur can be divided according to adaptation strategies as follows.

\subsection{Consonant Deletion}

The first strategy employed to analyze the same Sanskrit loanwords in Thai and Patani Malay is known as consonant deletion. Deletions in borrowed words are a way to make it easier for native speakers to pronounce those loanwords. The consonant which is deleted would not be 
replaced by other consonants in the recipient language. The most consonant deletion which occurs in this situation is syncope. Syncope is defined as the process of deletion of sounds from the interior of the word which is regularly found in Thai and Patani Malay.

\begin{tabular}{|c|c|c|c|c|c|c|}
\hline & Sanskrit & & Thai & & Patani Mala & \\
\hline (1) & kṛttikā & 'pleiades' & /krìttìka:/ & 'pleiades' & /kiøti:kə:/ & 'pleiades' \\
\hline (2) & pañjara & 'a cage' & /bancho:n/ & $\begin{array}{l}\text { 'a cage, window } \\
\text { in royal word' }\end{array}$ & /ріøја:ұэ:/ & 'prison' \\
\hline (3) & svara & 'voice' & /sàvárá?/ & 'voice' & /søo:rっ:/ & 'voice' \\
\hline (4) & prathama & 'primary' & /pràthŏm/ & 'primary’ & /pøita:mo:/ & 'primary' \\
\hline (5) & $\operatorname{argh}$ & 'worth' & /?øàk/ & 'worth' & /ha:yigs:/ & ‘worth' \\
\hline (6) & sarva & 'all of sorts' & /sàøp/ & 'all of sorts' & /siyibo:/ & 'all of sorts' \\
\hline
\end{tabular}

Examples (1) and (2) show that there are omissions of sound in the interior of words. The /t/ and $/ \tilde{n} /$ phonemes in Sanskrit words are undergone to be deleted while adapting into Patani Malay. Because there are only three final consonants in Patani Malay, $/ \mathrm{y} / / ? / / \mathrm{h} /$, which is less than in Sanskrit and Thai. Therefore, when borrowing words that have a final consonant that does not appear in Patani Malay, it is preferable to delete that sound. In contrast, Thai has eight phonemes as follows; / $\mathrm{k}, \mathrm{t}, \mathrm{p}, \mathrm{n}, \mathrm{y}, \mathrm{m}, \mathrm{j}, \mathrm{w} /$ in the final consonant position. It is more convenient to find nearby phonemes. In case, the sound is consistent, it will be preserved by others phonemes in Thai. As shown in the examples (2) / $\tilde{n} /$ dental nasal phoneme in Sanskrit replaced by $/ \mathrm{n} /$ alveolar nasal phoneme in Thai. In addition, examples (3) and (4) demonstrated how to break up consonant clusters that do not occur in Patani Malay. The consonant clusters /sv/ and /pr/ could not be found in Patani Malay. Therefore, deletion of the consonant cluster in the second phoneme position occurs. The phonemes $/ \mathrm{v} /$ and $/ \mathrm{r} /$ are deleted $/ \mathrm{v} /, / \mathrm{r} / \longrightarrow / \varnothing /$. On the other hand, those phonemes are preserved in Thai. This is because consonant cluster was found in Thai inventory, but they are still fewer than in Sanskrit. The phonemes that do not match are chosen by inserting a vowel as shown in the example (3). However, the same phoneme, such as /pr/ which is found both in Sanskrit and Thai will be retained as illustrated in the example (4). The same situation also occurs in Thai, as can be seen from the examples (5) and (6) where $/ \mathrm{r} /$ is omitted.

\subsection{Consonant Insertion}

Consonant insertion is another method of linguistic transformation. This process is rarely found both in Thai and Patani Malay. 


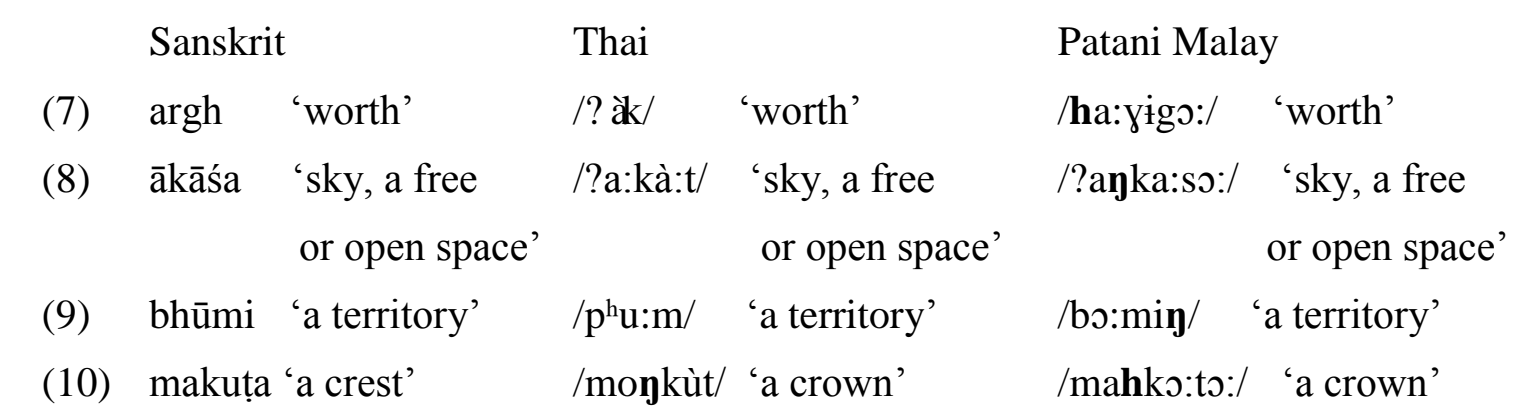

The data above indicate the insertion of consonants of Sanskrit loanwords in Thai and Patani Malay. For example (7), presents the insertion of the consonant in Patani Malay with the initial consonant. From data found only /h/ phoneme which insert in that position. In addition, there are three final consonants in Patani Malay inventory mentioned in 4.1 consonant deletion. In contrast, as can be seen above in the data (8), (9), and (10), found only two phonemes $/ \mathrm{y} /$, $/ \mathrm{h} /$ occur in the final consonant. Meanwhile, consonant insertion in Thai occurs only in final position as shown in data (10).

\subsection{Devoicing}

This is the process that involves a consonant that has previously been voiced, but it becomes voiceless when borrowed. This process occurs only in Thai language.

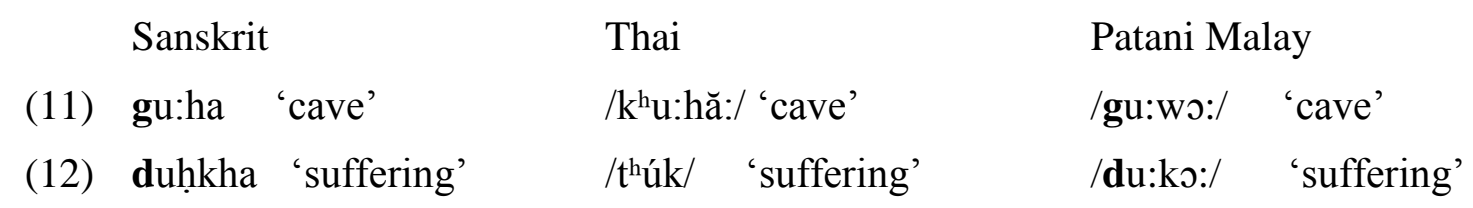

Based on examples (11) and (12), the manner of articulation of the phonemes $/ \mathrm{g} /$ and $/ \mathrm{d} / \mathrm{is}$ changed from a voiced unaspirated velar to $/ \mathrm{k}^{\mathrm{h}} /$ voiceless aspirated velar and voiced unaspirated dental to $/ \mathrm{t}^{\mathrm{h}} /$ voiceless aspirated alveolar respectively. Meanwhile Patani Malay still maintains those sounds.

\subsection{Voicing}

This is the process that is opposed to devoicing. The consonant is previously voiceless but it becomes voiced when borrowed as described in examples below. This process occurs only in Thai language.

\begin{tabular}{|c|c|c|c|}
\hline & Sanskrit & Thai & Patani Malay \\
\hline (13) & putrī 'a daughter' & /bùttri:/ 'a daughter' & /pitiyi:/ 'a princess' \\
\hline (14) & pañjara 'a cage’ & $\begin{array}{r}/ \text { banc }^{\mathrm{h}} \mathrm{\jmath}: \mathrm{n} / \text { 'a cage, window } \\
\text { in royal word' }\end{array}$ & /pija:ðə:/ \\
\hline
\end{tabular}

For examples (13) and (14), the manner of articulation of the phoneme /p/ is changed from a voiceless unaspirated bilabial to /b/ voiced unaspirated bilabial. Meanwhile Patani Malay still maintains those phonemes. 


\subsection{Consonant Substitution}

Consonant substitution is the process that helps language users produce the sound of the borrowed language that is absent in their language. This refers to a situation when one item is replaced or substituted by another item. This incident can be discovered in the Sanskrit loanwords both in Thai and Patani Malay. In the case of the Thai, not all consonants could be substituted when Sanskrit words are borrowed except fricative phonemes which will always replace that sound. The following examples show the consonants in Sanskrit loanwords undergo substitution when they are absorbed in Thai.

\begin{tabular}{llll}
\multicolumn{1}{l}{ Sanskrit } & Thai & Patani Malay \\
(15) śatru 'enemy' & /sàttru:/ 'enemy' & /sitiłu:/ 'enemy' \\
(16) śabda 'word' & /sàp/ 'word' & /sibido:/ 'word for prophet' \\
(17) bha:șa: 'language' & /ppa:să:/ 'language' & /ba:so:/ 'language'
\end{tabular}

As demonstrated in examples (15)-(17), /śs / fricative palatal and /ṣ/ fricative retroflex consonant in Sanskrit has adapted to /s/ fricative alveolar consonant in Thai. Because the Thai language does not have /ś/ and /ṣ/ phonemes in their inventory. It is difficult for Thai speakers pronounce the words. Therefore, the consonant must be replaced by another consonant that is very close to the recipient's language. For this reason, the phoneme is permanently substituted with /s/ in every word in Thai.

Similarly, the examples below (18)-(23) show the consonant substitution process which occurred with the consonants in Patani Malay. From the examples, phonemes /bh/, /ph/, /kh/, $/ \mathrm{th} /, / \mathrm{ch} /$ and $/ \mathrm{dh} /$ are substituted to other phonemes in Patani Malay as $/ \mathrm{b} /, / \mathrm{p} /, / \mathrm{k} /, / \mathrm{t} /, / \mathrm{c} /$ and /d/ respectively. It can be seen that the consonant substitution process in Patani Malay occurred with many phonemes more than in Thai. A consonant substitution process in Patani Malay mostly occurs with the aspirated phonemes in Sanskrit words. Although the phonemes in Patani Malay indicate the aspirated sound in inventory. But it is mainly used in Thai and Arabic loanwords such as $/ \mathrm{c}^{\mathrm{h}} \mathrm{u}$ ?/ 'dress' in Patani Malay borrowed from the Thai word $/ \mathrm{c}^{\mathrm{h} u}$ t/ 'dress'. Those phonemes need to be substituted for other consonants that are very similar to them. Therefore, the aspirated sound in Sanskrit is completely replaced by the unpirated sound in Patani Malay. Moreover, as presented in the examples (24)-(25), the /śs and /ș/ phonemes in Sanskrit are also substituted by /s/ alveolar fricative in every word as it happened in the Thai language as mentioned above.

Sanskrit

lobha 'greed'

phala 'result'

duhkha 'suffering'

katha: 'speech'

cha:ya: 'shade'

madhu 'honey'

śabda 'word'

bha:șa: 'language'
Thai

/lô:p/ 'greed'

/phŏn/ 'result'

/thúk/ 'suffering'

/kàthă:/ 'speech'

/chă:ja:/ 'shade'

/máthú?/ 'honey'

/sàp/ 'word'

/pha:să:/ 'language'
Patani Malay

/lo:bs:/ 'greed'

/pa:lo:/ 'result'

/du:ks:/ 'suffering'

/ka:ts:/ 'speech'

/ca:ys:/ 'shade'

/ma:du:/ 'bee'

/sibids:/ 'word for prophet'

/ba:so:/ 'language' 


\section{Conclusion}

Language contact is a phenomenon that can occur in all languages around the world. In Thai and Patani Malay, likewise, both languages have caused a language contact phenomenon for a long time. The language contact that influenced Thai and Patani Malay from the beginning is the Sanskrit language which came into both languages through religion and culture. The present research discusses consonant changes resulted from 210 shared Sanskrit loanwords in Thai and Patani Malay. The findings of this research found that there are five types of consonant adaptations that occurred in Sanskrit loanwords are consonant deletion, consonant insertion, devoicing, voicing, and consonant substitution.

In the case of consonant deletion, It can be seen that the consonant deletion takes place mostly in a word-medial position to make pronunciation as simple and easy as possible. Consonant deletion can be described as occurring with consonants which not found in Thai and Patani Malay. Besides, it occurs with cluster consonants especially Patani Malay which does not have cluster consonants in its system. Therefore, deletion occurs to break up the consonant cluster. In contrast, Thai is often preserved because it has cluster consonants as well. On the other hand, consonant insertion occurs in both languages. This is for easier pronunciation as well. In addition, voicing and devoicing are specific happened to the Thai language. Because the sound system of Thai language has an aspirated and unaspirated in pairs of sounds, therefore can occur alternately. The transformation of both languages follows the linguistic rules. However, there can be some non-coordinated variations, such as eliminating or adding sounds, based on factors in the consonant system of each language. But the change taking place in the same direction is the consonant substitution, especially fricative sounds. The results fulfilled and answered the research objective. It was expected that the findings would be helpful for both language users. This study investigated only consonant changes, but further studies might examine sound changes in other perspectives.

\section{References}

Arlotto, A. (1972). Introduction to historical linguistics. Boston, MA: Houghton Mifflin.

Bualert, P. (1993). Compound Words in Pattani Malay (Unpublished master's thesis). Chulalongkorn University, Thailand.

Buaphanngam, S. (2017). Vowel Changes in Pali and Sanskrit Loanwords in Thai. Damrong Journal, 16(1), 149-174.

Burusphat, S. (2000). Dialect geography. Nakorn Phathom: Mahidol University Press.

Campbell, L. (1999). Historical linguistics: An introduction. Massachusetts, MA: MIT Press.

Chaipunya, C. S. (2018). The Survey of Research Works on Pali-Sanskrit Loanwords. Academic Journal of Humanities and Social Sciences Burapha University, 26(51), 188-211.

Chaiyanara, P. M. (1979). Sanskrit in Malay language. Pattani, Thailand: Prince of Songkla University Press.

Chanthao, R. (20011). Lexical Borrowing from Thai and Lexical Change in Lao: A Semantic Field Analysis. Unpublished Ph.D. 's thesis. Mahidol University, Thailand. 


\section{Macrothink}

International Journal of Linguistics

ISSN 1948-5425

2021, Vol. 13, No. 5

Coedes, G. (1975). The Indianized States of Southeast Asia. Canberra, Australia: Australian National University Press.

Crowley, T., \& Bowern, C. (2010). An introduction to historical linguistics (4th ed.). New York: Oxford University.

Faculty of Humanities and Social Sciences. (1984). Patani Malay-Thai Dictionary. Pattani: Prince of Songkla University Press.

Hayes, B. P. (2010). Introductory Linguistics. Los Angeles: University of California.

Hussain, Q., Mahmood, R., \& Mahmood, A. M. (2011). Vowel Substitution: A Comparative Study of English Loans in Punjabi and Urdu. International Journal of Linguistics, 3(1), E31. https://doi.org/10.5296/ijl.v3i1.1022

Iemwanthong, K. (2008). Acoustic characteristics of Pattani Malay vowels. Unpublished master's thesis. Chulalongkorn University, Thailand.

Institute of Southeast Asian Maritime States Studies. (2008). Patani Malay-Thai Dictionary. Pattani: Prince of Songkla University Press.

Kaseng, A. (2001). Arabic Loanwords in Pattani Malay. Unpublished master's thesis. Chulalongkorn University, Thailand.

Lehiste, I. (1988). Lectures on language Contact. London: MIT Press.

Lehmann, W. P. (1973). Historical linguistics: An introduction. Texas, USA: Holt, Rinehart and Winston.

Matras, Y. (2009). Language Contact. Cambridge: Cambridge University Press.

Mehdi, M. F., \& Jaradat, M. (2021). Adverbs of Time in Arabic and English: Comparative Study. International Journal of Linguistics, 13(1), 85-97.

Millar, M. (2007). Historical Linguistics (2nd ed.). London: Hodder Arnold.

Monier, W. (1999). Sanskrit-English dictionary. New Delhi, India: Bharatiya.

Naziman, S. N. M., \& Jaafar, S. R. S. (2018). The Adaptation Strategies of English Loanwords among Kelantan Malay Dialect Speakers. 3L: The Southeast Asian Journal of English Language Studies, 24(4), 128-142.

Ninlapan, P. (1993). Expressive in Pattani Malay. Unpublished master's thesis. Mahidol University. Thailand.

Paramal, W. (1991). Long Consonants in Pattani Malay: The Result of Word and Phrase Shortening. Unpublished master's thesis. Mahidol University, Thailand.

Pengpala, P. (2006). Characteristics comparison between Thai and Pali-Sanskrit. Ramkhamhaeng Journal, 26(1), 19-23.

Perry, E. D. (1936). A Sanskrit primer. New York, NY: Columbia University Press.

Phatyarat, P. (1980). Sanskrit Words in Patani Malay. Unpublished master's thesis. Chulalongkorn University, Thailand. 


\section{Macrothink}

International Journal of Linguistics

ISSN 1948-5425

2021, Vol. 13, No. 5

Ramana, M. V. (2001). Impact of Sanskrit on Southeast Asia. In Proceedings of International Sanskrit Conference on Sanskrit in Southeast Asia: The Harmonizing Factor of Cultures, Bangkok, Thailand.

Resource Center for Revitalization and Maintenance of Language and Cultures, Research Institute for Languages and Cultures of Asia. (2015). Patani Malay-Thai Dictionary. Nakhon Pathom, Thailand: Mahidol University Press.

Royal Institute of Thailand. (2010). Guide to writing system in Patani Malay with Thai alphabet. Bangkok, Thailand: Office of the Royal Society of Thailand.

Royal Institute of Thailand. (2011). Thai dictionary. Bangkok, Thailand: Office of the Royal Society of Thailand.

Salae, R. (1991). Malay dialects in Southern Thailand. Songkhla, Thailand: Srinakharinwirot Songkhla University Press.

Salzmann, Z. (2012). Language, Culture and Society: An Introduction to Linguistic Anthropology (5th ed.). Colorado: Westview.

Sarapadnuke, C. (2001). Influence of Sanskrit on Thai Language. In Proceedings of International Sanskrit Conference on Sanskrit in Southeast Asia: The Harmonizing Factor of Cultures, Bangkok, Thailand.

Treffers-Daller, J. (2010). Borrowing, Handbook of Pragmatics Online. Retrieved from https://benjamins.com/online/hop/articles/bor1

Tuaycharoen, P. (2004). Overview of education Phonetics and linguistics (3rd ed.). Bangkok: Thammasat University.

Umaiyah, H. U. (2010). Lexical borrowing between Austronesian and Tai- Kadai language families: Focus on Malay and Thai languages. Language and Culture Journal, 29(1), 5-34.

Uthai, R. (2013). Sub-grouping of the Malay dialects spoken in five Southern border provinces of Thailand (TRF Publication No. PDF4480088). Retrieved from https://elibrary.trf.or.th/project_content.asp?PJID=PDF4480088

\section{Copyrights}

Copyright for this article is retained by the author(s), with first publication rights granted to the journal.

This is an open-access article distributed under the terms and conditions of the Creative Commons Attribution license (http://creativecommons.org/licenses/by/4.0/) 